\title{
ESTUDOS VISANDO A SÍNTESE DE BIODIESEL A PARTIR DO ÓLEO DE COCO VERDE
}

\section{ARTIGO ORIGINAL}

LOPES, Vinicius Antonio ${ }^{1}$

BAÚ, Rosana Zanetti ${ }^{2}$

LOPES, Vinicius Antonio. BAÚ, Rosana Zanetti. Estudos visando a síntese de biodiesel a partir do óleo de coco verde. Revista Científica Multidisciplinar Núcleo do Conhecimento. Ano 05, Ed. 05, Vol. 08, pp. 17-30. Maio de 2020. ISSN: 2448-0959, Link de acesso: https://www.nucleodoconhecimento.com.br/engenhariaquimica/sintese-de-biodiesel

\section{RESUMO}

Este trabalho teve como objetivo a obtenção de biodiesel a partir de uma reação de transesterificação dos ácidos graxos presentes no óleo de coco usando-se dois tipos de catalisadores básicos, visando ao melhor rendimento do biocombustível. Foram realizadas análises de suas propriedades físicas, como $\mathrm{pH}$ e densidade comparandose com os parâmetros definidos pela Agência Nacional do Petróleo, Gás Natural e Biocombustíveis (ANP). Testes químicos do grupo funcional éster foram realizados para caracterização do biodiesel, além de estudos de cromatografia gasosa para determinação de ésteres metílicos baseados na norma EN 14103 do European Standards.

\footnotetext{
${ }^{1}$ Estudante de Engenharia Química na Universidade São Francisco.

2 Grupo de Pesquisas em Meio Ambiente e Sustentabilidade/ Universidade São Francisco (GPMAS/USF); Mestre em Química Orgânica pela UNICAMP, Licenciada em Química pela UNICAMP.
} 
Palavras-Chave: Transesterificação, ácidos graxos, fonte renovável.

\section{INTRODUÇÃO}

O biodiesel é um biocombustível que vem ganhando mercado e se desenvolvendo com o apoio de inúmeras indústrias e universidades, as quais investem em pesquisas nessa área, a fim de obter biocombustíveis de fontes renováveis e de forma economicamente viável (MA, 1999). Apesar de haver um grande questionamento sobre o impacto da produção do biodiesel no meio ambiente, pois o mesmo pode causar esgotamento de solo, desmatamento e erosão, a matéria-prima utilizada para este projeto é proveniente de resíduos de coco descartados em praias ou em estabelecimentos que oferecem o produto, de modo a reaproveitar o que seria destinado ao lixo. Dados sobre a produção de coco verde no Brasil mostram que há grande quantidade dessa fruta sendo descartada anualmente e suas propriedades demonstram que o óleo de coco é uma matéria prima viável para obtenção de biodiesel, podendo gerar renda devido à sua coleta e valor agregado ao resíduo (DABDOUB et al., 2009; GRUPO FRAGMAQ, 2017).

A literatura relata a obtenção de biodiesel por diversas outras fontes de biomassa, como semente de girassol (GAMA et al., 2010), milho, palma (JITPUTTI et al., 2006), microalgas (FRANCO et al., 2013) e soja (GERIS et al., 2007) e há estudos envolvendo o processo de transesterificação com o óleo de coco, usando vários catalisadores, (MACHADO et al., 2006, RAMOS FILHO et al., 2016)

A molécula do biodiesel é um éster de cadeia longa que geralmente é obtido através de uma reação de transesterificação de triglicerídeos com um álcool, catalisada por uma base (OLIVEIRA et al., 2017). Na reação, as moléculas do triglicerídeo são quebradas produzindo três moléculas de ésteres, que é o biodiesel em questão, e uma molécula de glicerol (VICENTE et al., 2004). 
Figura 1 - Reação de transesterificação de um triglicerídeo.<smiles></smiles>

Triglicerídeo $+\quad 3 \mathrm{R} \cdot \mathrm{OH}$

Álcool

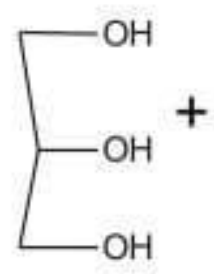

Glicerol<smiles></smiles>

Ésteres

Fonte: VICENTE et al., 2004.

Com isso, teve-se a ideia de realizar a síntese do biodiesel a partir do óleo do coco verde, por uma reação de transesterificação de ácidos graxos com dois diferentes catalisadores ( $\mathrm{KOH}$ - hidróxido de potássio e $\mathrm{NaOH}$ - hidróxido de sódio), onde os mesmos permitem obter uma reação mais rápida, podendo aumentar a produção gerando um ganho maior em condições de produção em larga escala (OLIVEIRA et al., 2013; RAMOS FILHO et al., 2016).

O óleo de coco apresenta uma composição rica de ácidos graxos tendo como principais componentes os ácidos láurico e mirístico, conforme demonstrado na Tabela 1. Assim, deve-se esperar também que o biodiesel obtido se apresente como uma mistura de ésteres de cadeia longa (SILVA; MACHADO, 2017). 
Tabela 1 - Composição média do óleo de coco.

\begin{tabular}{cccc}
\hline $\begin{array}{c}\text { Ácidos Graxos (\%) e índice } \\
\text { de iodo }\end{array}$ & $\begin{array}{c}\text { MARTIN \& GUICHARD } \\
(1979)\end{array}$ & $\begin{array}{c}\text { WHITE } \\
(1992)\end{array}$ & $\begin{array}{c}\text { ROSSELL } \\
(1993)\end{array}$ \\
\hline Capróico & nd & 0,4 & nd \\
Caprílico & nd & 5,3 & 5,5 \\
Cáprico & nd & 5,9 & 5,5 \\
Láurico & $44-47$ & 44,2 & 43 \\
Mirístico & $15-18$ & 15,8 & 16 \\
Palmítico & $6-9$ & 8,6 & 9 \\
Esteárico & $3-5$ & 2,9 & 3,5 \\
Oléico & $12-16$ & 15,1 & 15 \\
Linoléico & $1-2$ & 1,7 & 2,6 \\
İ́ndice de Iodo & $14-18$ & $13-18$ & $14-18$ \\
\hline
\end{tabular}

Fonte: MACHADO et al., 2006.

Como se observa na Figura 2, numa reação química o papel do catalisador é fundamental, pois o mesmo diminui a energia de ativação da reação entre os reagentes, percorrendo o caminho da reação com energia mais baixa, obtendo o produto com maior velocidade e menor gasto energético (ATKINS, 2018).

A partir desse conceito consegue-se planejar a produção em escala industrial para fornecimento dessa fonte de biocombustível em todo o país com o intuito de substituir os combustíveis provenientes de petróleo, emitindo menos compostos poluentes que contribuem para o efeito estufa, sem haver mudanças mecânicas nos motores de ignição por compressão e, ainda, gerando um rendimento econômico grande ao país pelo barateamento do processo e não dependência de países exportadores de combustíveis, além de estimular a produção do mesmo em seu próprio território (FRANCO et al., 2013; GAMA et al., 2010, JITPUTTI et al., 2006). 
Figura 2 - Representação de uma reação com e sem catalisador.

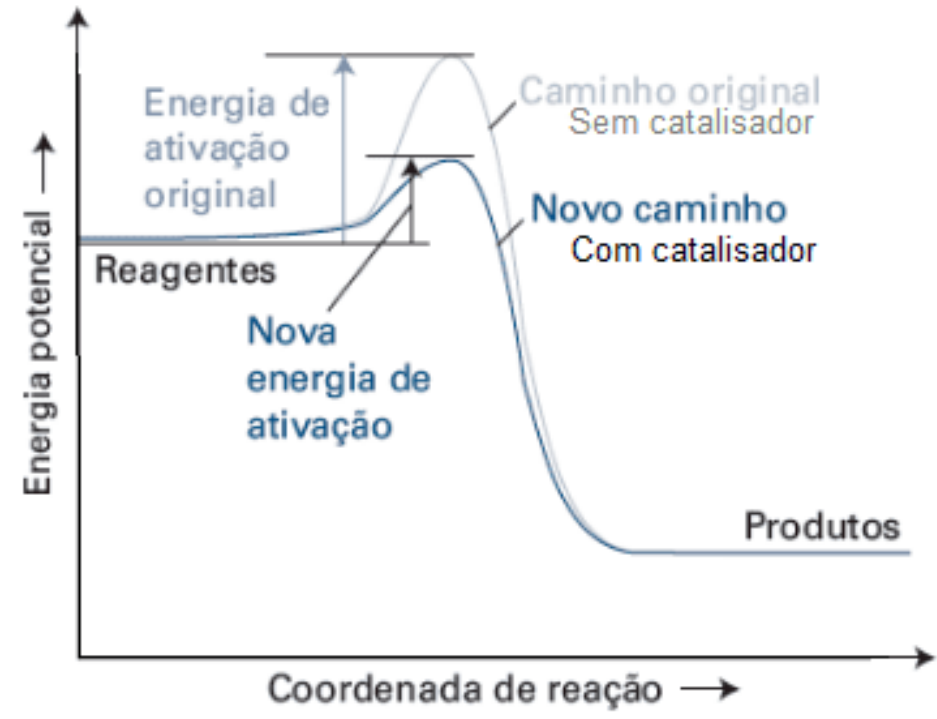

Fonte: ATKINS, 2018.

O objetivo deste trabalho consiste em obter o biodiesel através do óleo de coco utilizando-se $\mathrm{KOH}$ e $\mathrm{NaOH}$ como catalisadores. Pretende-se comparar o rendimento obtido pelos dois catalisadores analisando-se algumas propriedades físicas e sua composição em ésteres metílicos.

\section{METODOLOGIA}

O método de transesterificação escolhido utilizando-se dois tipos de catalisadores básicos e a metodologia empregada se baseou no procedimento desenvolvido por Oliveira e colaboradores (2013). Após a obtenção do óleo, o mesmo foi analisado para testar a presença do grupo funcional éster utilizando-se hidroxilamina clorídrica (VOGEL, 1980). Análise por cromatografia gasosa foi realizada pelo equipamento da marca Agilent, modelo GC7890, para determinação da composição do óleo e comparação com parâmetros já estabelecidos pela norma EN 14103 do European Standards. Por fim, foram realizadas medidas de $\mathrm{pH}$, usando um indicador universal e medidas de densidade utilizando a técnica do picnômetro (CÉSAR; PAOLI; ANDRADE, 2018) 


\subsection{OBTENÇÃO DO BIODIESEL POR TRANSESTERIFICAÇÃO DE UM TRIGLICERÍDEO}

A reação foi executada em capela. Preparou-se um banho-maria em uma chapa de aquecimento provida de agitação magnética a $65-70^{\circ} \mathrm{C}$. Assegurou-se que a temperatura estivesse estável neste intervalo. Pesou-se 0,2 g de $\mathrm{KOH}$ (ou NaOH) em um béquer de $50 \mathrm{~mL}$. Sobre o sólido adicionaram-se $8 \mathrm{~mL}$ de álcool metílico. Agitouse até a dissolução completa do sólido. Pesaram-se $20 \mathrm{~mL}$ de óleo de coco, o qual foi transferido para um balão de fundo redondo de $125 \mathrm{~mL}$. Adicionou-se a solução alcoólica ao óleo. Conectou-se um condensador de refluxo ao balão. Aqueceu-se a mistura no banho-maria, agitando-a vigorosamente por um período de 1 hora. Passado esse tempo, adicionou-se ao balão, pela parte superior do condensador, uma mistura de $12 \mathrm{~mL}$ de álcool metílico e $0,3 \mathrm{~mL}$ de $\mathrm{H}_{2} \mathrm{SO}_{4}$. A reação seguiu por mais 1 hora. Ao final deste tempo, filtrou-se a mistura à pressão reduzida. Transferiu-se o filtrado para um balão de $125 \mathrm{~mL}$. A mistura foi levada ao rotaevaporador para eliminação de excesso de álcool. Fez-se a transferência da mistura para um funil de separação de $125 \mathrm{~mL}$, a qual foi deixada por $15 \mathrm{~min}$ em repouso para separação completa das fases. Separou-se e pesou-se a fase inferior, a glicerina. Foram introduzidos $10 \mathrm{~mL}$ de água deionizada a $70{ }^{\circ} \mathrm{C}$ com leve agitação. Manteve-se a mistura em repouso por 15 min e então a lavagem foi repetida. Transferiu-se o biodiesel para um balão de fundo redondo e foi levado novamente ao rotaevaporador para eliminação da umidade (OLIVEIRA et al., 2013).

\subsection{TESTE FUNCIONAL PARA ÉSTERES}

- Pré-Teste: Dissolveu-se cerca de $50 \mathrm{mg}$ da amostra a ser testada em $1 \mathrm{ml}$ de etanol e adicionou-se $1 \mathrm{ml}$ de ácido clorídrico $1 \mathrm{M}$. Foi adicionada, então, 1 gota de solução aquosa de cloreto férrico a 5\% e observou-se se houve o aparecimento de cor laranja, vermelha ou violeta. Se alguma dessas cores tivesse aparecido, o teste não teria sido válido. 
- Teste funcional: Colocou-se, em um tubo de ensaio, cerca de $50 \mathrm{mg}$ da substância a ser analisada, $1 \mathrm{~mL}$ de solução etanólica $0,5 \mathrm{M}$ de hidroxilamina clorídrica e 0,2 mL de hidróxido de sódio a $20 \%$. Aqueceu-se a mistura até a ebulição, esfriando-a um pouco e adicionaram-se $2 \mathrm{~mL}$ de ácido clorídrico $1 \mathrm{M}$. Caso houvesse turvação, seria adicionado cerca de $2 \mathrm{~mL}$ de etanol. Adicionou-se 1 a 2 gotas de solução aquosa de cloreto férrico a $5 \%$ e observou-se o aparecimento de cor, a qual foi comparada com a do teste preliminar. A cor vinho ou violeta, comparada com a coloração amarelada do teste preliminar, confirmou a presença do grupo éster (VOGEL, 1980).

\subsection{MÉTODO DE CROMATOGRAFIA PARA DETECÇÃO DE ÉSTERES METÍLICOS}

Por métodos experimentais e baseados na norma EN 14103 do European Standards, foram determinados os seguintes parâmetros para a realização da cromatografia gasosa (DUVEKOT, 2011):

Tabela 2 - Parâmetros para realização da cromatografia gasosa

\begin{tabular}{|c|c|}
\hline & Method 1 \\
\hline $\begin{array}{l}\text { Carrier Gas: } \\
\text { Hydrogen }\end{array}$ & $40 \mathrm{ml} / \mathrm{min}$ \\
\hline Start Temperature & $130^{\circ} \mathrm{C}$ \\
\hline Hold Time & $4 \mathrm{~min}$ \\
\hline Heating Rate & $5^{\circ} \mathrm{C} / \mathrm{min}$ \\
\hline Final Temperature & $300^{\circ} \mathrm{C}$ \\
\hline Injection Volume & $1 \mu \mathrm{l}$ \\
\hline $\begin{array}{l}\text { Column } \quad \text { Fused } \\
\text { Silica }\end{array}$ & $\begin{array}{l}30 \mathrm{~m} \times 0,25 \mathrm{~mm} \\
\times 0,25 \mu \mathrm{m}\end{array}$ \\
\hline Detector & FID \\
\hline
\end{tabular}

Fonte: Próprio autor. 


\section{RESULTADOS E DISCUSSÃO}

Utilizando-se $\mathrm{KOH}$ como catalisador na reação de transesterificação para se obter o biodiesel, obteve-se rendimento de 37,59\% de Glicerina e 62,41\% de biocombustível, o qual apresentou $\mathrm{pH}=7$. Usando-se $\mathrm{NaOH}$ como catalisador obteve-se um rendimento de $29,52 \%$ de glicerina e $70,48 \%$ de biocombustível, o qual apresentou $\mathrm{pH}=0$. Como se observa na figura $3 \mathrm{~b}$, o produto se apresenta com coloração levemente amarelada e translúcida.

A determinação do teor de glicerina livre foi realizada pelo método volumétrico e segue recomendação da Agência Nacional do Petróleo, Gás Natural e Biocombustíveis (ANP), estando de acordo com a NBR 15771.

Figura 3 - a) Verificação do pH das amostras de biodiesel. b) Separação da glicerina e do biodiesel por decantação.
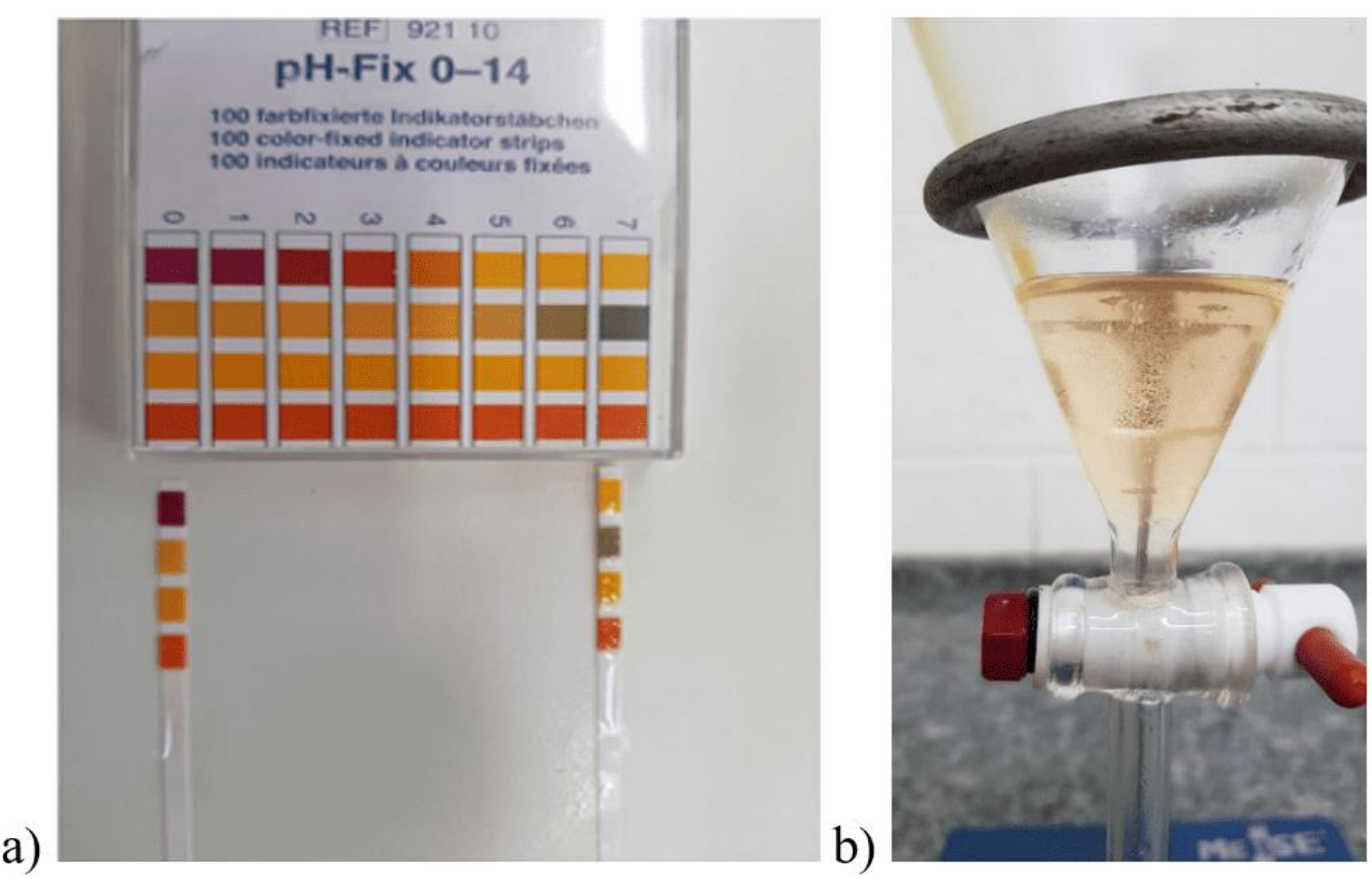

Fonte: Próprio autor.

Disponível em: https://www.nucleodoconhecimento.com.br/engenharia-quimica/sintese-debiodiesel 
Após esses resultados, foi feito um teste químico para o grupo funcional orgânico Éster. Os ésteres de ácidos carboxílicos costumam reagir com a Hidroxilamina e o cloreto de ferro III, ocorrendo uma mudança de cor para o violeta/vinho, onde a intensidade pode variar de acordo com a molécula de éster que está sendo analisada (figuras $4 \mathrm{c}$ e d). Os pré-testes indicaram que o produto a ser analisado não produziria interferência na coloração final (figuras $4 a$ e b).

Ambas as reações foram catálisadas em meio básico, sendo que tanto com hidróxido de sódio, quanto com hidróxido de potássio, após o teste com a hidroxilamina clorídrica e cloreto de ferro III, observa-se a mudança de cor que comprova a obtenção de ésteres na solução, tendo como produto o biodiesel. A intensidade da cor pode ter sido influenciada pelas impurezas que podiam estar presentes na solução.

Figura 4- a) Pré-teste da reação com $\mathrm{NaOH}$. b) Pré-teste da reação com $\mathrm{KOH}$. c) Teste de grupo funcional da reação com $\mathrm{NaOH}$. d) Teste de grupo funcional da reação com $\mathrm{KOH}$.
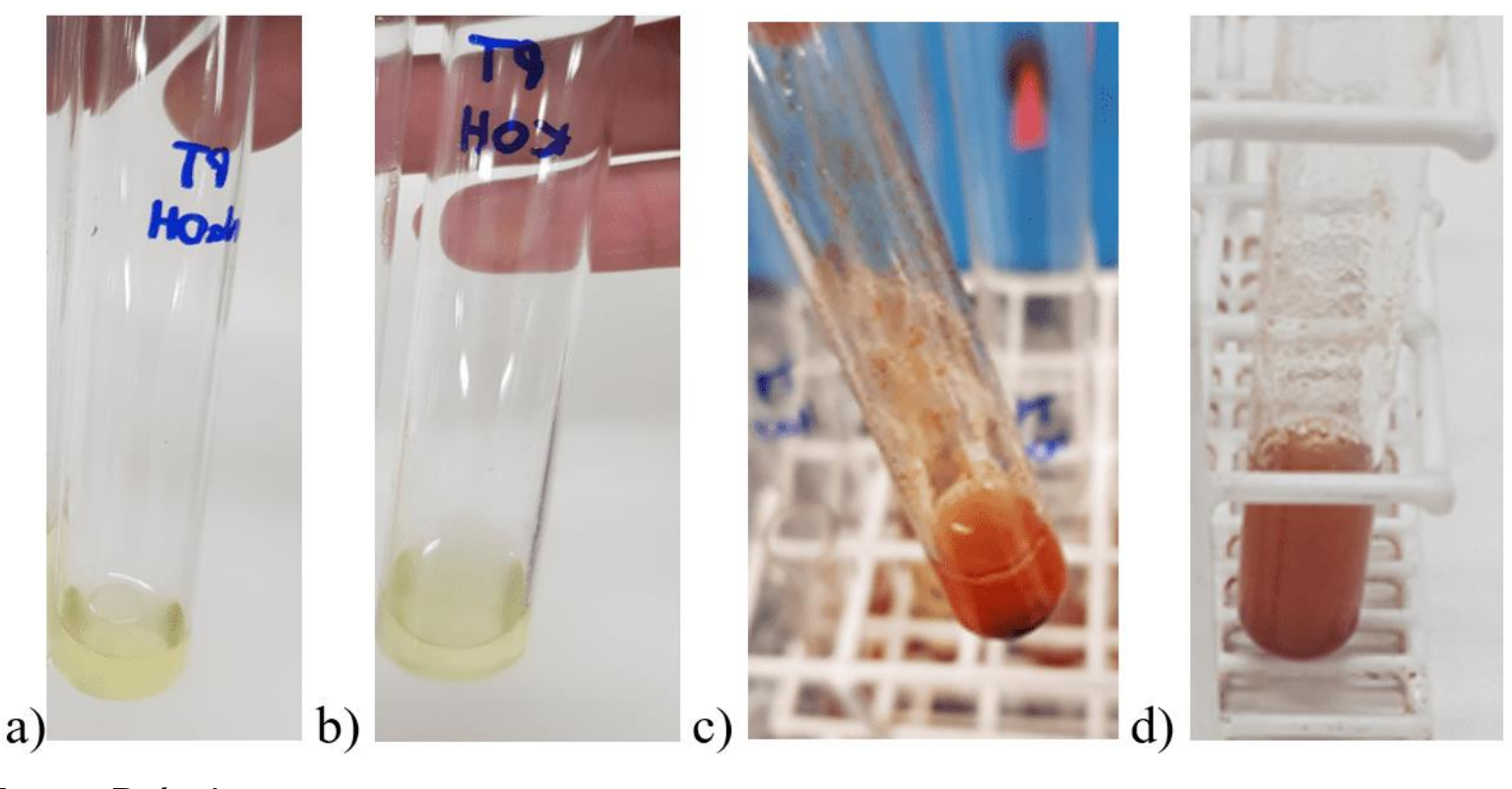

Fonte: Próprio autor.

Após os testes de grupo funcional foram realizadas análises por cromatografia gasosa, para se determinar a composição de cada biodiesel obtido. Como padrão de 
comparação utilizou-se o cromatograma fornecido pelo Petroleum Analysers for Labs \& Process (PAC) (Figura 5) como referência, para se analisar a composição do biodiesel obtido neste trabalho acrescentando-se no procedimento mais 2 minutos de tempo de retenção na coluna.

Figura 5 - Cromatograma de referência dos ésteres metílicos: C6 a C24.

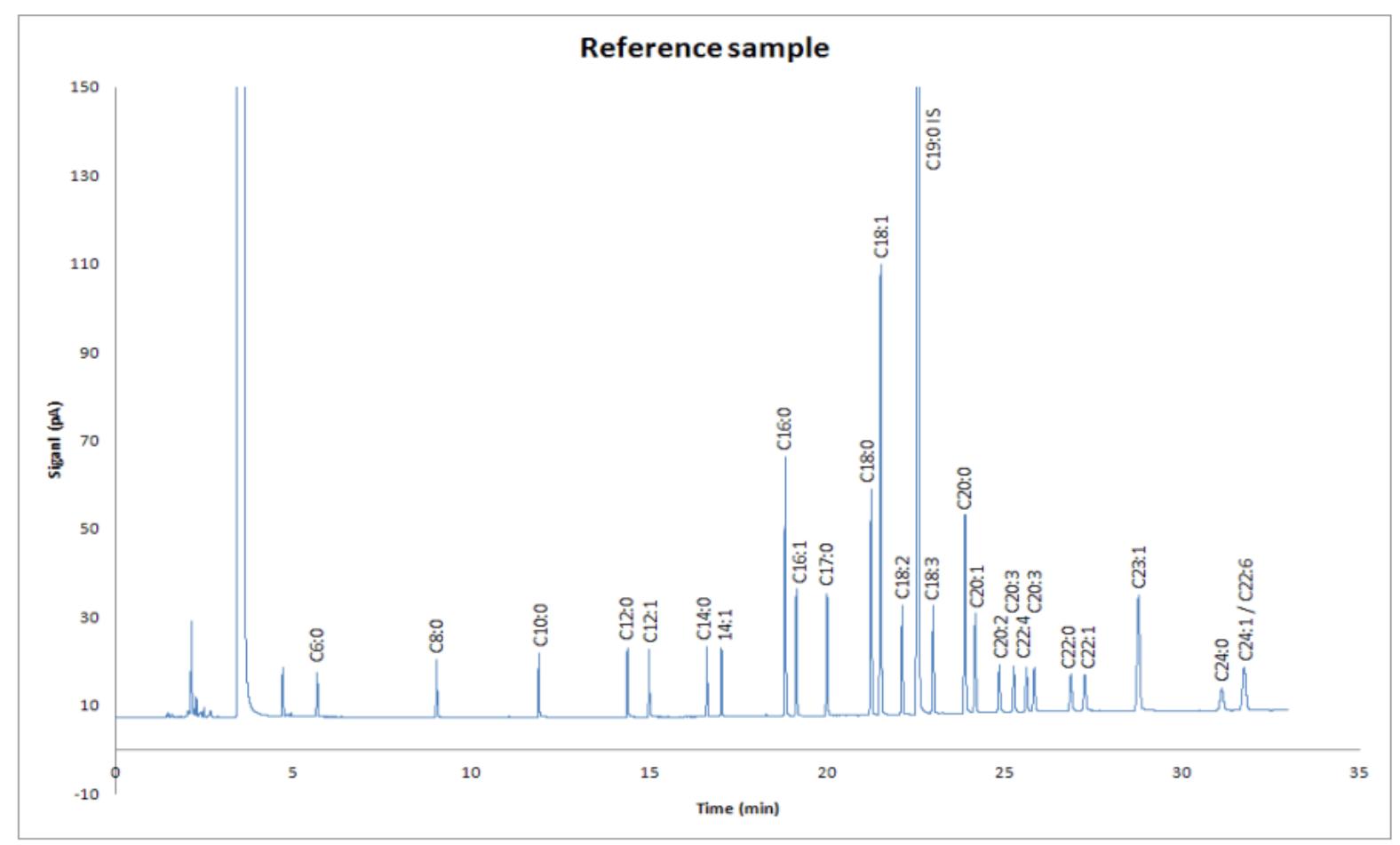

Fonte: PAC, 2012.

A determinação do teor total de ésteres por Cromatografia Gasosa está de acordo com a NBR 15764 e segue recomendação da ANP.

Para um double check, foram feitas análises de cromatografia gasosa para determinação da quantidade total de ésteres metílicos nos biocombustíveis obtidos, de acordo com o método EN 14103 do European Standards, cujos resultados são relevantes para validação do estudo. 
Figura 6 - Gráfico gerado pelo detector do cromatógrafo gasoso: a) reação com $\mathrm{KOH}$; b) reação com $\mathrm{NaOH}$.

a)

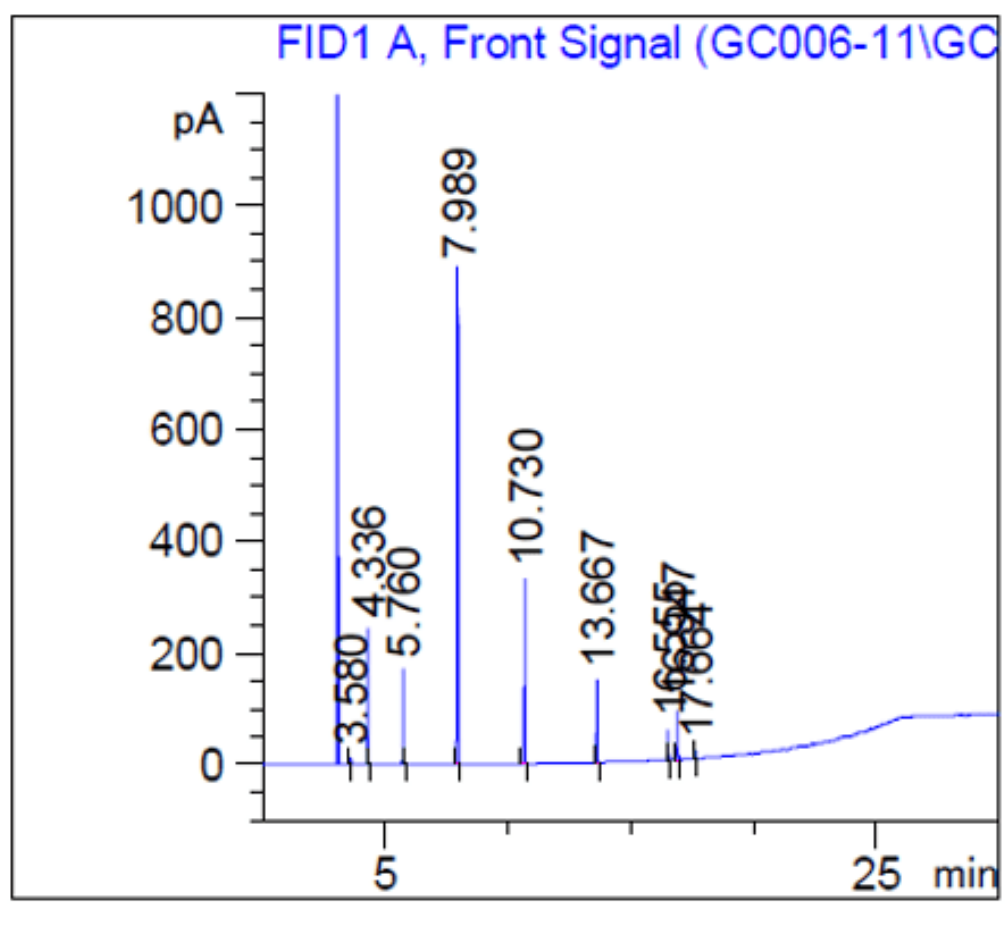

b)

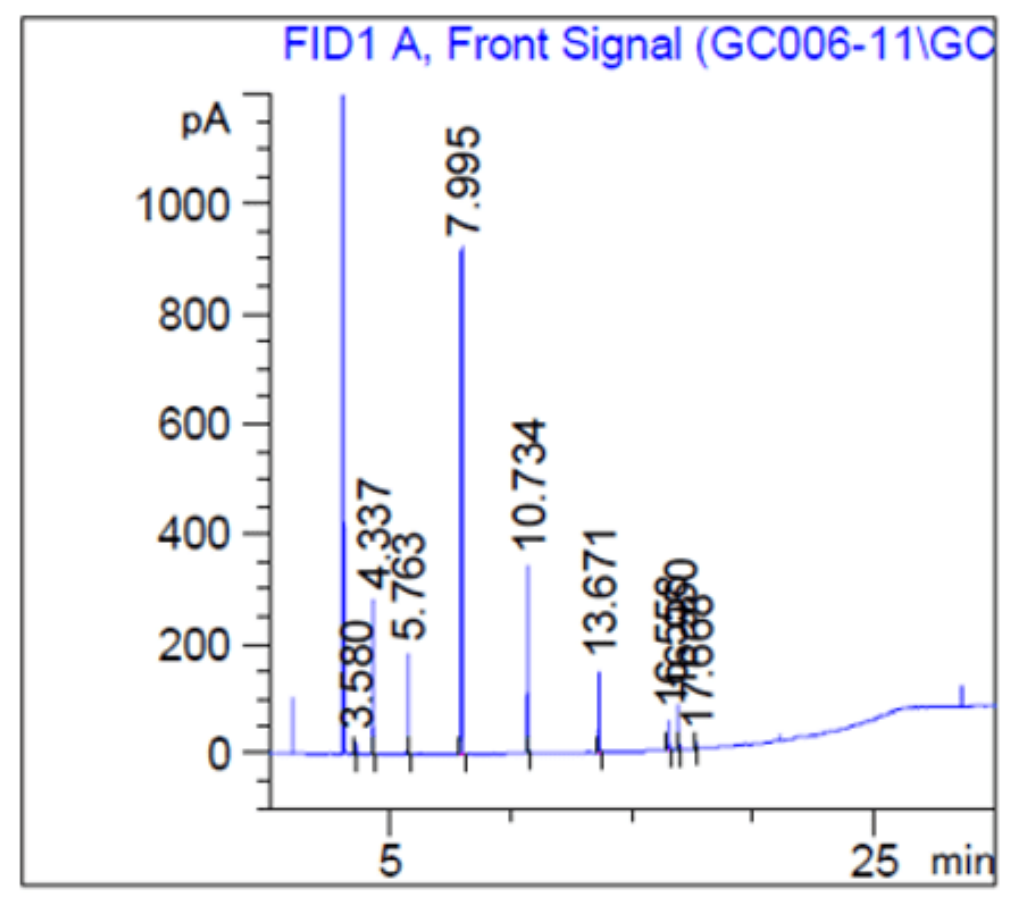

Fonte: Próprio autor.

RC: 50912

Disponível em: https://www.nucleodoconhecimento.com.br/engenharia-quimica/sintese-debiodiesel 
Com o relatório da cromatografia (Figura 6), pode-se observar a detecção (FID) de moléculas de ésteres metílicos, onde se encontram diferentes cadeias carbônicas, como C6:0, C8:0, C10:0 e, principalmente, C12:0, já que o óleo de coco é rico em ácido láurico, conforme descrito na Tabela 1, tendo uma porcentagem de éster láurico de $49,9 \%$ com $\mathrm{KOH}$ como catalisador e de $49,7 \%$ com $\mathrm{NaOH}$, além dos demais compostos, sendo esse biodiesel, então, uma mistura de ésteres, conforme dados descritos na Tabela 3.

Tabela 3 - Cálculo das porcentagens de cada éster metílico detectada e seu tempo de retenção: a) $\mathrm{KOH}$ como catalisador; b) $\mathrm{NaOH}$ como catalisador.

\begin{tabular}{|c|c|c|c|c|c|c|}
\hline $\begin{array}{c}\text { Peak } \\
\#\end{array}$ & $\begin{array}{c}\text { RetTime } \\
\text { [min] }\end{array}$ & Type & $\begin{array}{l}\text { Width } \\
\text { [min] }\end{array}$ & $\begin{array}{r}\text { Area } \\
{\left[\mathrm{pA}^{*} \mathrm{~s}\right]}\end{array}$ & $\begin{array}{l}\text { Height } \\
{[\mathrm{pA}]}\end{array}$ & $\begin{array}{c}\text { Area } \\
\%\end{array}$ \\
\hline & & & & $1--.-1$ & 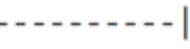 & \\
\hline 1 & 3.580 & BB & 0.0162 & 21.75073 & 20.74709 & 0.54373 \\
\hline 2 & 4.337 & BB & 0.0180 & 335.36154 & 278.58459 & 8.38339 \\
\hline 3 & 5.763 & BB & 0.0230 & 266.06329 & 182.79173 & 6.65107 \\
\hline 4 & 7.995 & BB & 0.0313 & 1997.11462 & 920.65533 & 49.92401 \\
\hline 5 & 10.734 & BB & 0.0339 & 730.60748 & 342.99878 & 18.26377 \\
\hline 6 & 13.671 & BB & 0.0332 & 316.28842 & 146.70409 & 7.90660 \\
\hline 7 & 16.558 & BB & 0.0365 & 120.46598 & 53.04460 & 3.01142 \\
\hline 8 & 16.950 & BB & 0.0348 & 182.48299 & 82.54304 & 4.56172 \\
\hline 9 & 17.668 & BB & 0.0349 & 30.17422 & 13.60431 & 0.75430 \\
\hline
\end{tabular}

a)

$$
\text { Totals : }
$$

4000.309292041 .67357

\begin{tabular}{|c|c|c|c|c|c|c|}
\hline $\begin{array}{c}\text { Peak } \\
\#\end{array}$ & $\begin{array}{l}\text { RetTime } \\
\text { [min] }\end{array}$ & Type & $\begin{array}{l}\text { Width } \\
\text { [min] }\end{array}$ & $\begin{array}{r}\text { Area } \\
{\left[\mathrm{pA}^{*} \mathrm{~s}\right]}\end{array}$ & $\begin{array}{l}\text { Height } \\
{[\mathrm{pA}]}\end{array}$ & $\begin{array}{c}\text { Area } \\
\%\end{array}$ \\
\hline & & & - & | - - & 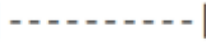 & | - - \\
\hline 1 & 3.580 & BB & 0.0163 & 13.58713 & 12.86507 & 0.35521 \\
\hline 2 & 4.336 & BB & 0.0188 & 286.39957 & 241.49649 & 7.48730 \\
\hline 3 & 5.760 & BB & 0.0227 & 242.68878 & 169.76604 & 6.34457 \\
\hline 4 & 7.989 & BB & 0.0331 & 1900.58301 & 881.82928 & 49.68662 \\
\hline 5 & 10.730 & BB & 0.0320 & 709.61261 & 330.58801 & 18.55128 \\
\hline 6 & 13.667 & BB & 0.0333 & 320.36920 & 147.76874 & 8.37536 \\
\hline 7 & 16.555 & BB & 0.0355 & 122.69492 & 54.02174 & 3.20759 \\
\hline 8 & 16.947 & BB & 0.0361 & 195.80492 & 87.36083 & 5.11890 \\
\hline 9 & 17.664 & BB & 0.0355 & 33.39997 & 14.69291 & 0.87317 \\
\hline Tota & : & & & 3825.14011 & 1940.38912 & \\
\hline
\end{tabular}

Fonte: Próprio autor.

Disponível em: https://www.nucleodoconhecimento.com.br/engenharia-quimica/sintese-debiodiesel 
De acordo com a Agência Nacional do Petróleo, Gás Natural e Biocombustíveis (ANP), deve-se ter no mínimo $96,5 \%$ de teor de éster, sendo assim, somando as porcentagens, temos $97,9905 \%$ (na reação com $\mathrm{KOH}$ ) e 99,0732\% (na reação com $\mathrm{NaOH}$ ). As duas amostras se encontram dentro dos padrões preestabelecidos.

A última análise realizada foi a determinação da densidade de cada biodiesel, utilizando-se um picnômetro de 5,00 ml e um de 25,00 ml, previamente calibrados, aplicando-se a fórmula da densidade, $(\mathrm{g} / \mathrm{ml})$.

- Cálculo para o biodiesel com KOH como catalisador

$$
d=\frac{6,3360}{5,00}=1,27 \mathrm{~g} / \mathrm{ml}
$$

- Cálculo para o biodiesel com $\mathrm{NaOH}$ como catalisador

$$
d=\frac{23,4075}{25,00}=0,94 \mathrm{~g} / \mathrm{ml}
$$

Conforme a Resolução $\mathrm{n}^{\circ}$ 7, publicada em 2008 pela ANP, o biodiesel deve ter densidade inferior a $3,0 \mathrm{~kg} / \mathrm{m}^{3}$ para ser comercializado, o que equivale a $3,0 \mathrm{~g} / \mathrm{ml}$. Sendo assim, ambos os produtos obtidos estão dentro dos parâmetros estabelecidos pela ANP e, portanto, têm os índices de qualidade requeridos para sua produção em larga escala.

Como perspectivas futuras sabe-se que outros parâmetros ainda devem ser analisados, como ponto de fulgor, índice de acidez, entre outros. Pretende-se realizar todos as análises requeridas e implementar um projeto piloto para produção do biodiesel em reator químico, analisando-se a cinética do processo e estabelecendose parâmetros de controle e viabilidade econômica do processo. 


\section{CONCLUSÃO}

Observou-se que foi possível fazer a reação de transesterificação e a obtenção do biodiesel tendo como referência todos os testes experimentais e seus resultados. Sendo seu rendimento, respectivamente, $37,59 \%$ de glicerina e $62,41 \%$ de biocombustível e $\mathrm{pH}=7$ com $\mathrm{KOH}$ como catalisador, e 29,52\% de glicerina e 70,48\% de biocombustível e $\mathrm{pH}=0, \mathrm{com} \mathrm{NaOH}$ como catalisador. Sua função orgânica (éster) foi comprovada através de um teste químico e, pela cromatografia gasosa, foi possível determinar o teor de cada éster formado, tendo seus resultados positivos para determinação do biodiesel. Com esses resultados conclui-se que o objetivo do trabalho foi atingido, sendo possível obter o biodiesel através de um resíduo da biomassa nos parâmetros exigidos pela Agência Nacional do Petróleo, Gás Natural e Biocombustíveis - ANP, mostrando que é possível sua reprodutibilidade para, então, realizar estudos visando aumentar a escala de produção.

\section{REFERÊNCIAS}

ATKINS, Peter. Físico-Química - Fundamentos, 6ª edição. Rio de Janeiro: Livros Técnicos e Científicos ed., 2018, p. 243.

BRASIL, Agência Nacional do Petróleo, Gás Natural e Biocombustíveis. Resolução ANP № 7, de 19/03/2008, Diário Oficial da União, 20/03/2008.

CÉSAR, J.; PAOLI, M.-A. D.; ANDRADE, J. C. DE. A determinação da densidade de sólidos e líquidos. Revista Chemkeys, n. 7, p. 1-8, 2018.

DABDOUB, Miguel J. et al. Biodiesel: visão crítica do status atual e perspectivas na academia e na indústria. Quim Nova, v. 32, n. 3, p. 776-792, 2009.

DUVEKOT, Coen. Determination of total FAME and Linolenic acid methyl esters in Biodiesel according to EN-14103. Agilent Technologies, 2011. Disponível em: https://www.agilent.com/cs/library/applications/5990-8983EN.pdf. Acesso em: 14 jun. 2019. 
FRANCO, André Luiz Custódio et al. Biodiesel de microalgas: avanços e desafios. Quim Nova, São Paulo, 36, n. 3, p. 437-448, 2013.

GAMA, Paola Ervatti et al. Produção de biodiesel através de transesterificação in situ de sementes de girassol via catálise homogênea e heterogênea. Quim Nova, São Paulo, v. 33, n. 9, p. 1859-1862, 2010.

GERIS, Regina et al. Biodiesel de soja: reação de transesterificação para aulas práticas de química orgânica. Quim Nova, São Paulo, v. 30, n. 5, p. 1369-1373, 2007.

GRUPO FRAGMAQ. Entenda a importância da utilização do biodiesel para o Brasil, suas vantagens e desvantagens, 2017. Disponível em: https://www.fragmaq.com.br/blog/entenda-importancia-da-utilizacao-do-biodieselpara-o-brasil-suas-vantagens-e-desvantagens/. Acesso em: 14 jun. 2019.

JITPUTTI, Jaturong et al. Transesterification of Palm Kernel Oil and Coconut Oil by Difference Solid Catalysts. As. J. Energy Env., v. 7, n. 4, p. 423-433, 2006.

MA, Frangrui et al. Biodiesel production: a review. Bioresource Techonology, Elsevier Science, n. 70, p. 1-15, 1999.

MACHADO, Getúlio Costa et al. Composição em ácidos graxos e caracterização física e química de óleos hidrogenados de coco babaçu. Revista Ceres, Universidade Federal de Viçosa, MG; v. 53, n. 308, p. 463-470, 2006.

OLIVEIRA, Ana Flávia Alves et al. Transesterificação do acetato de etila com metanol: avaliação termodinâmica. The Journal of Engineering and Exact Sciences, v. 3, n. 3, p. 499-506, 2017.

OLIVEIRA, Diogo Müller et al. Obtenção de biodiesel por transesterificação em dois estágios e sua caracterização por cromatografia gasosa: óleos e gorduras em laboratório de química orgânica. Quim Nova, São Paulo, v. 36, n. 5, p. 734-737, 2013. 
PAC - Petroleum Analysers for Labs \& Process, 2012. Determination of total FAME and Linolenic acid methyl esters in Biodiesel according to EN-14103. Disponível em: http://www.paclp.com/tenants/pac/documents/ac_en14103_totalfame_biodiesel.pdf. Acesso em: 14 jun. 2019.

RAMOS FILHO, Jose Airton da Silva et al. Obtenção de biocombustível a partir de óleo de coco via catálise heterogênea. Encontros Universitários da UFC, Fortaleza, v. 1, n. 1, 2016.

SILVA, Larissa Vieira da; MACHADO, Camille Quarteroli. Identificação dos ácidos graxos láurico, caprílico e cáprico em óleos de coco artesanais por cromatografia gasosa acoplada ao espectrômetro de massas. In: CONGRESSO NACIONAL DE ALIMENTOS E NUTRIÇÃO, 3., CONGRESSO, NACIONAL DE ALIMENTAÇÃO E NUTRIÇÃO, 6., 2017, Ouro Preto, MG. Anais...Ouro Preto, MG, 2017, n. 4.

VICENTE, Gemma et al. Integrated biodiesel production: a comparison of different homogeneous catalysts systems. Science B. V. Bioresource Technology, n. 92, p. 397305, 2004.

VOGEL, A. I. Química orgânica: análise orgânica qualitativa. 3. ed. Rio de Janeiro: Livro Técnico S.A, 1980. v. 2.

Enviado: Setembro, 2019.

Aprovado: Maio, 2020. 